\title{
Etnografía de una enfermedad social (1994-2017)
}

Ethnography of a social disease (1994-2017)

\section{PePE MIRALLES}

\section{UNIVERSIDAD POLITÉCNICA DE VALÈNCIA (ESPAÑA) jmiralle@pin.upv.es}

Profesor y artista visual, en los últimos años ha impartido distintos seminarios y conferencias, participado en congresos y creado grupos de trabajo artístico, todo ello relacionado con las problemáticas que el VIH/Sida y la homosexualidad han evidenciado en los contextos sociales. Sus trabajos visuales circulan entre el espacio público, la imagen y la información, utilizando la figura del proyecto como eje genérico de su trabajo.

En los tramos de hospitalización domiciliaria, que atendíamos por turnos un grupo reducido de sus amistades, un día le pregunté si me proporcionaba los restos del material sanitario que estaba utilizando. Tenía que hacer una exposición y había algo en aquellos objetos que lograba vincularse con otros trabajos anteriores. De esta manera podría continuar con el intento de construir una etnografía del sida, un tema en el que andaba metido desde hacía ya unos años. Aceptó sin dudarlo. A partir de entonces, las cosas que Juan Guillermo utilizaba, me las guardaba dentro de bolsas de plástico. A la sazón no sabía que, de alguna manera, me estaba dando su cuerpo a trozos.

Botes de plástico con fórmulas magistrales que habitaban inútilmente en su estómago; bolsas con hierbas que circulaban en caída libre a través de su esófago tres veces al día, y que compró a un farsante que le aseguraba que con eso se curaría; jeringuillas con las que atravesábamos sus venas y nalgas esperando una mejoría del presagio semanal; gasas manchadas de antiséptico para desinfectar las heridas, porque había que poner mucho cuidado en eliminar los gérmenes externos que pudieran infectar su cuerpo vulnerable; guantes médicos que mitigaban el temido contacto con su sangre; bolsas de suero glucosado para tratar la pérdida de fluidos y dar aporte calórico a todo el organismo; paquetes de gasas para limpiar su piel irritada; frascos para almacenar medicamentos inyectables que aliviaban su dolor; catéteres de inserción venal que como bocas de hombre mantenían el cuerpo 
abierto para los goteros diarios; termómetros que median su fiebre persistente; pomadas que calmaban sus erupciones cutáneas; apósitos adhesivos para cerrar sus heridas; contenedores de residuos para agujas en los que se almacenaban de manera segura sus desperdicios; sistemas de infusión de suero que trasladaban el líquido inútil desde su recipiente suspendido a su cuerpo tendido; láminas elásticas autoadhesivas para asegurar que sus canales abiertos no se movieran; blíster para cápsulas que almacenaban ordenadamente su esperanza; cajas de AZT cuyo eco era inaudible.

Todos estos objetos fueron convirtiéndose en una colección de recuerdos, huellas e identificaciones que estaban preparándose para paliar la ausencia del cuerpo, ya que luego lo sustituyeron; y del tiempo, dado que su presencia rememora su uso y los ritos asociados que pautaban los momentos del día.

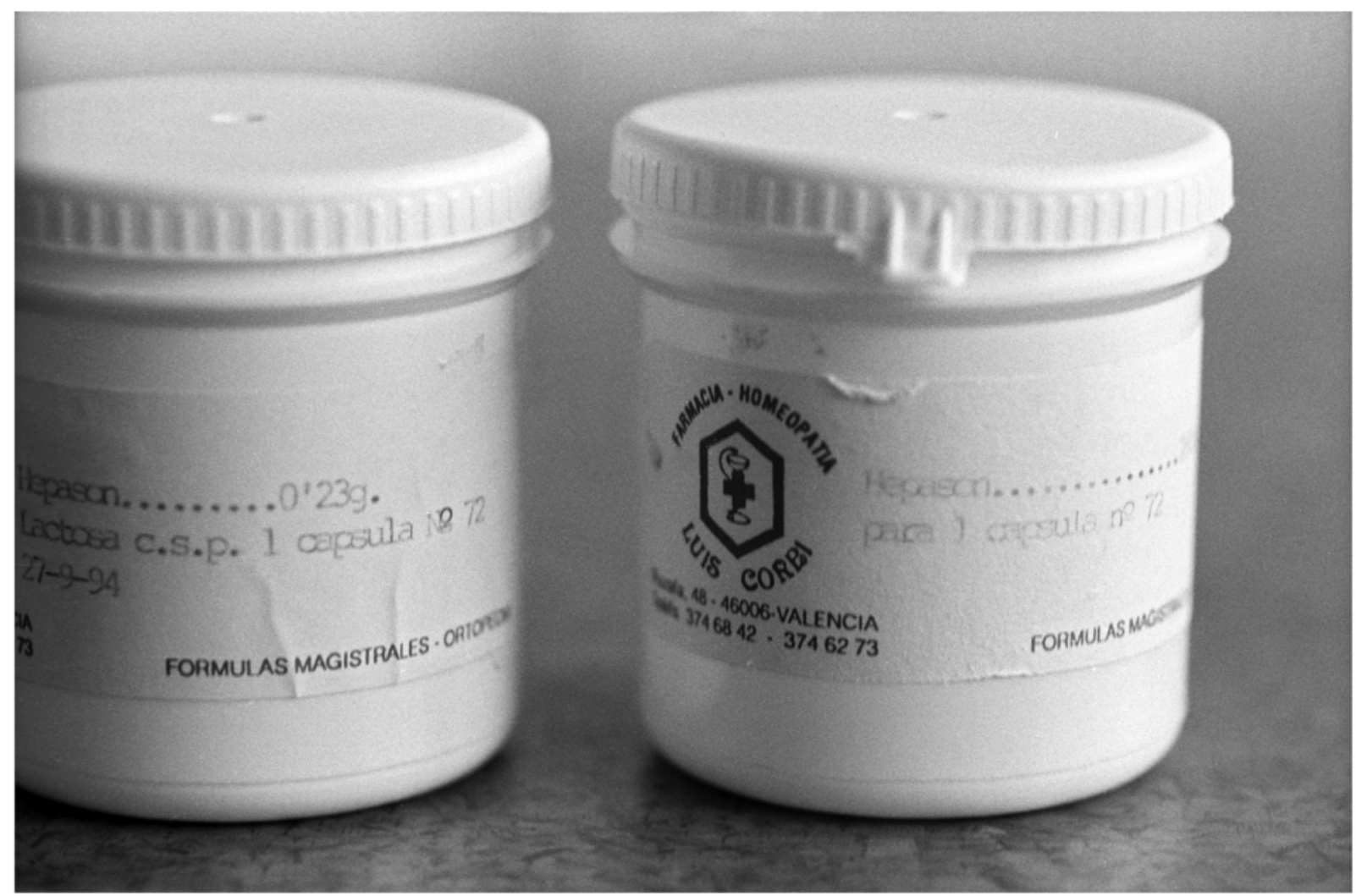



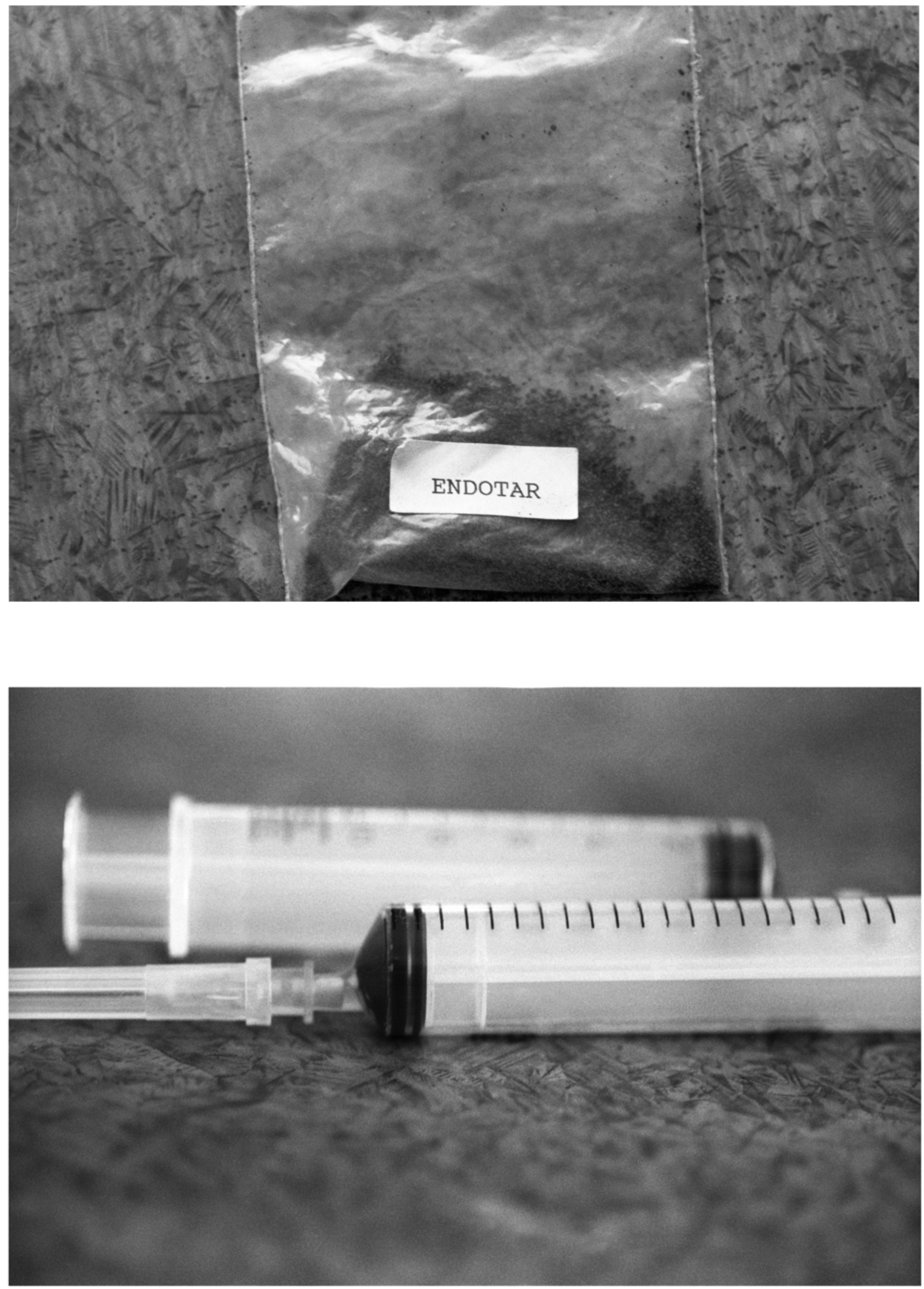

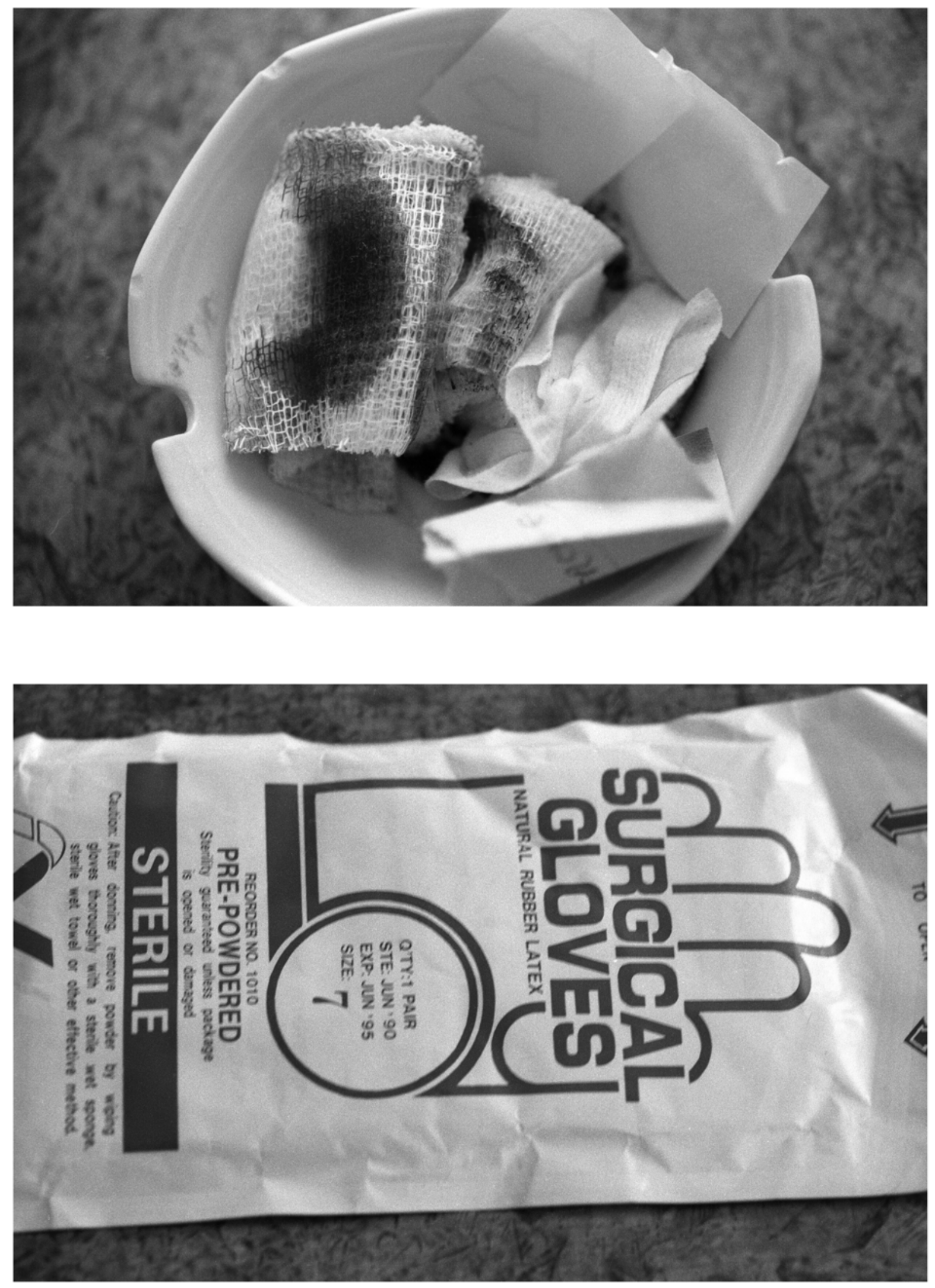

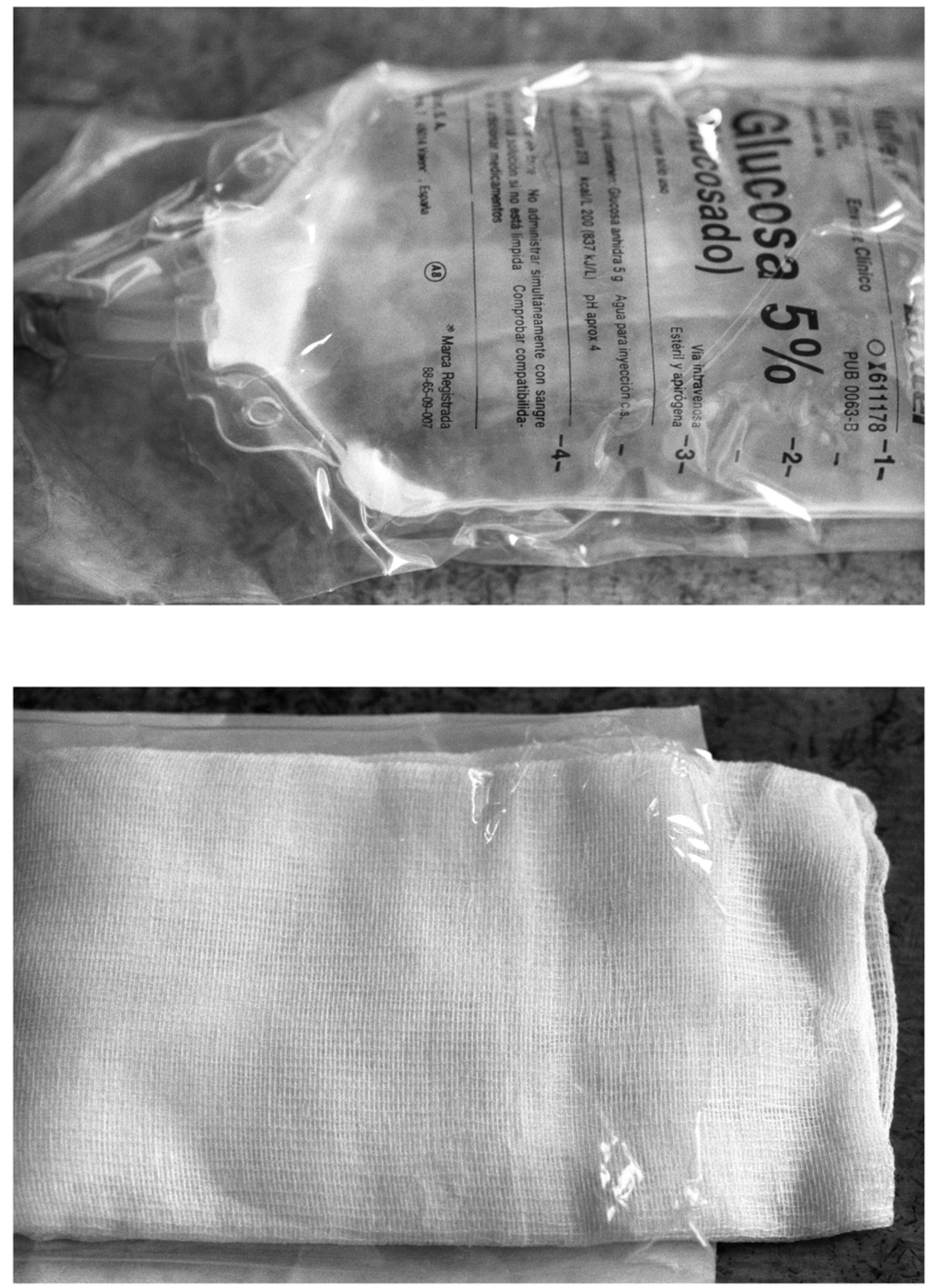

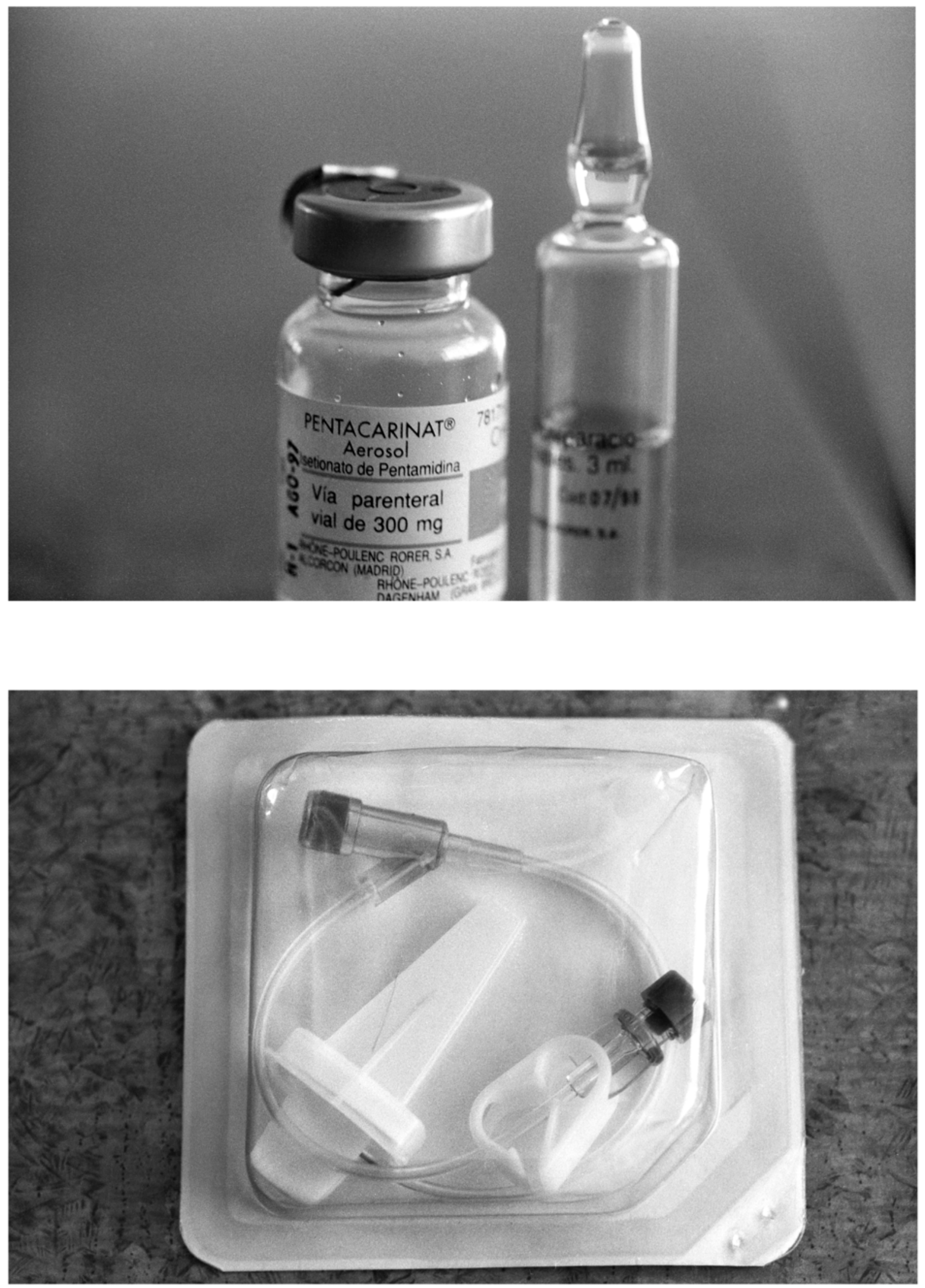

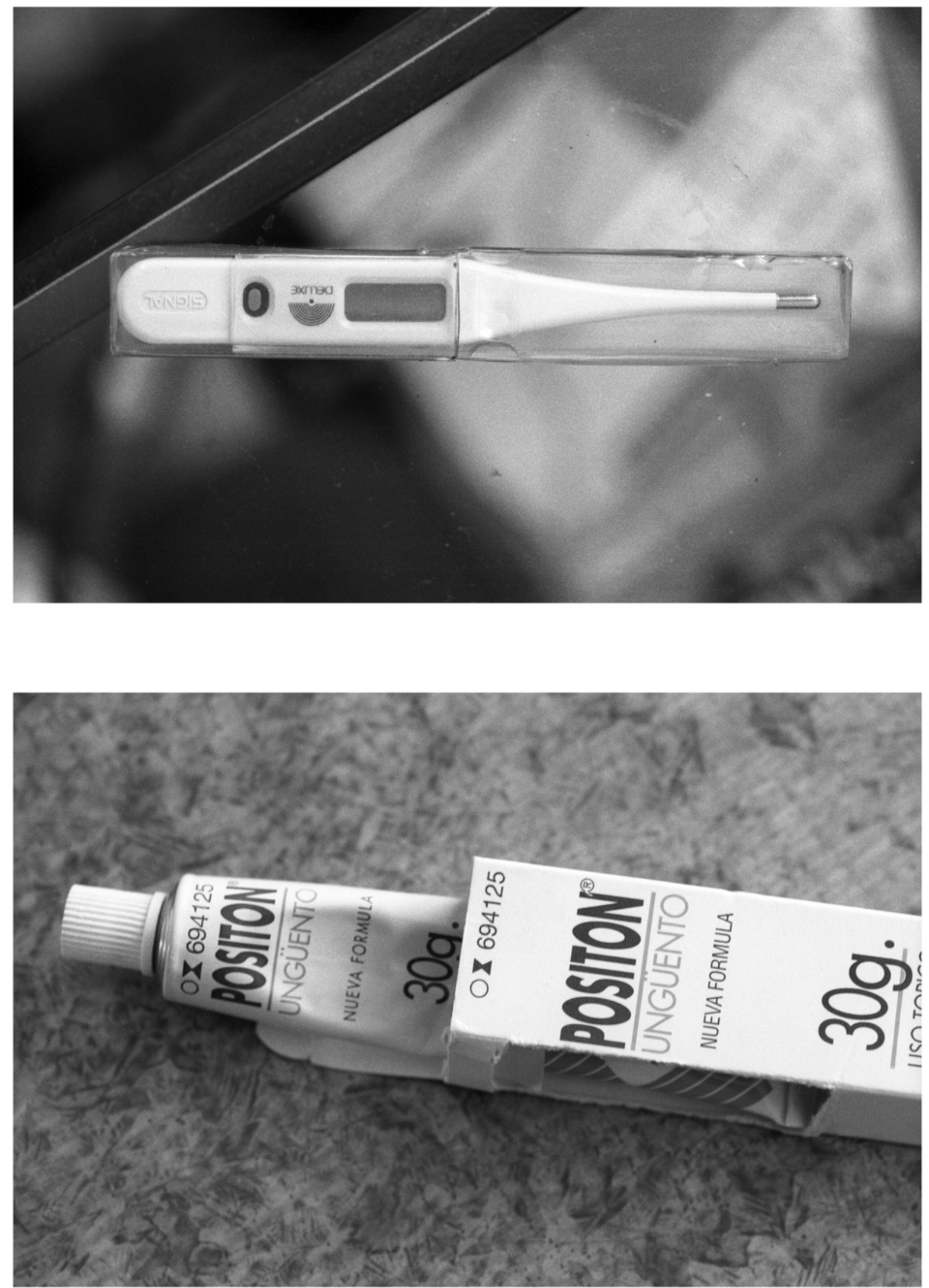

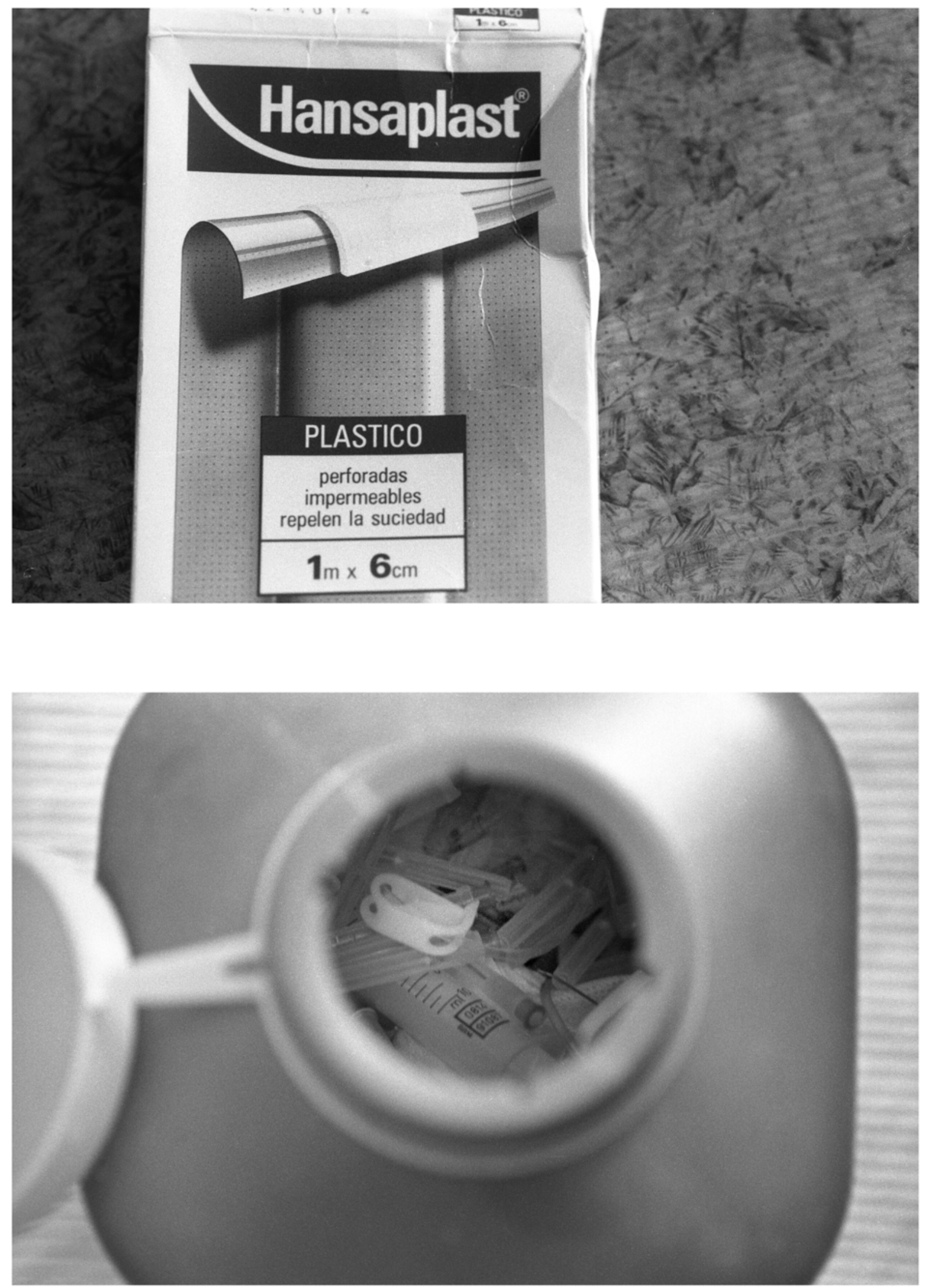

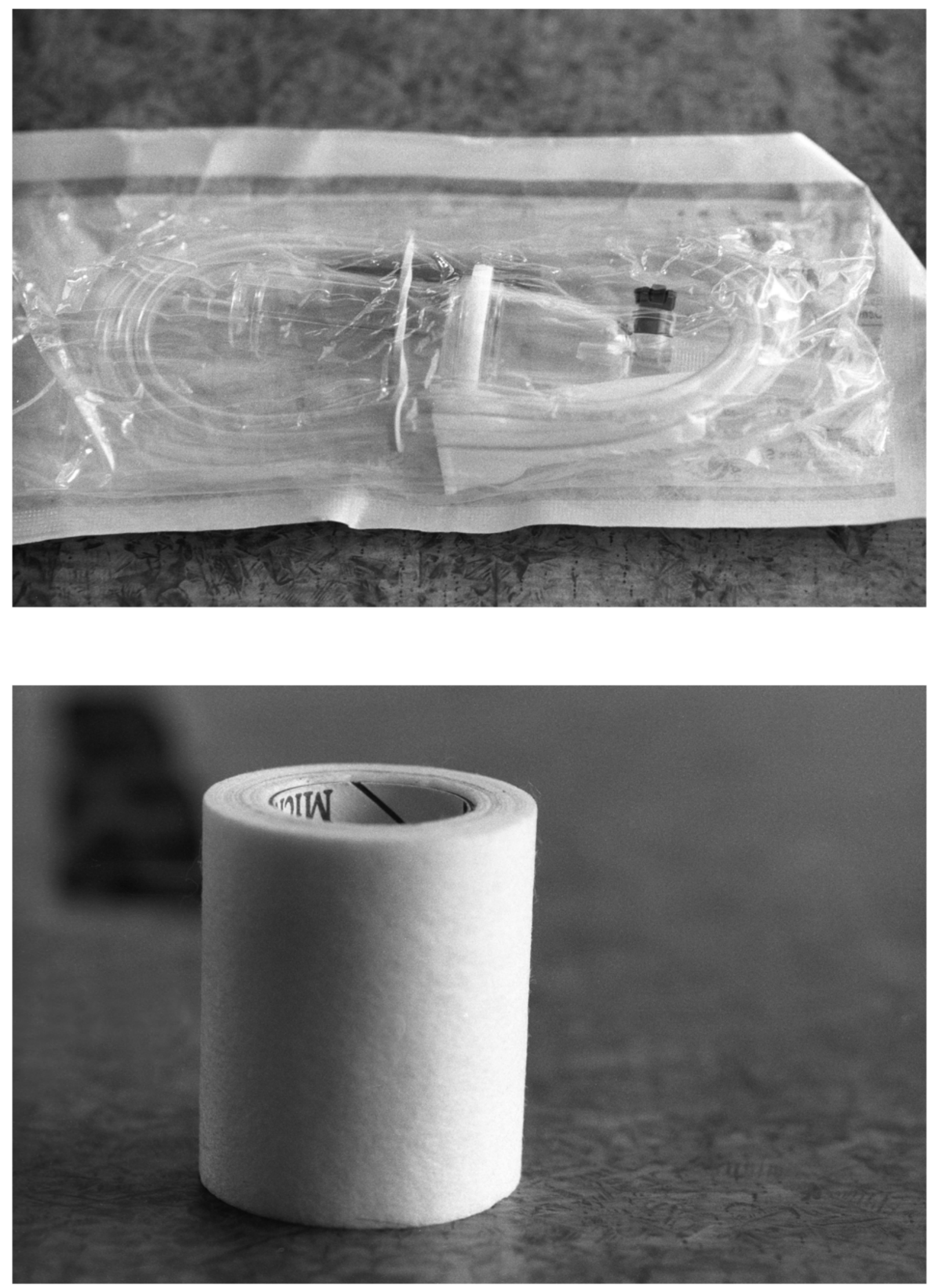


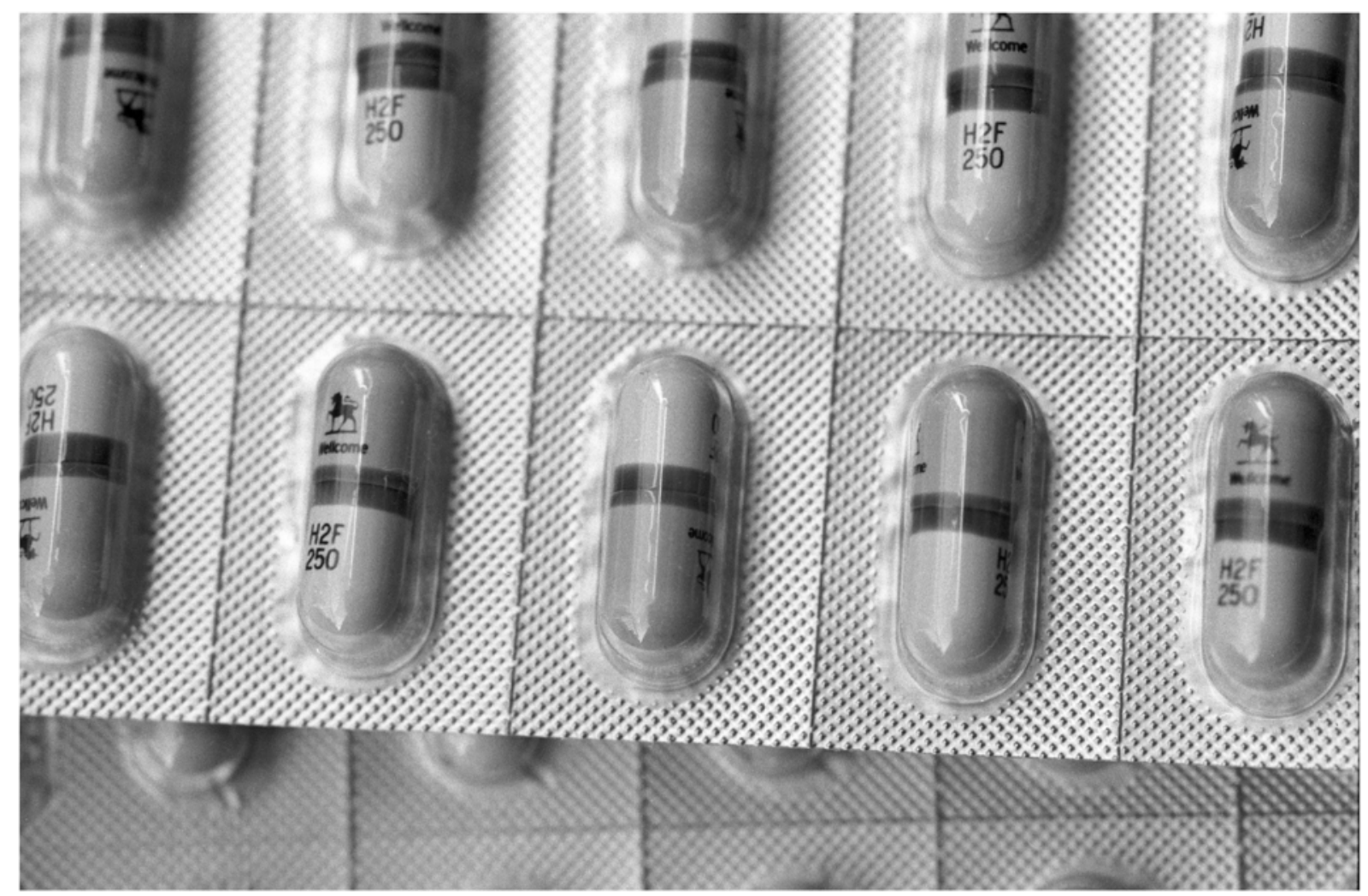

Retrovir

Zidovudina

P.V.P. IVA3- 29.97

$250 \mathrm{mg}$

P.V:P. 29.106 Ptas

40 cápsulas

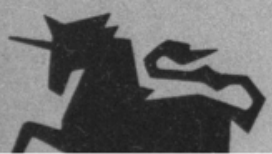


